\title{
Newly identified chemicals preserve mitochondrial capacity and decelerate loss of photoreceptor cells in murine retinal degeneration models
}

Craig Beeson ${ }^{1}$, Yuri Peterson ${ }^{1}$, Nathan Perron ${ }^{1}$, Mausumi Bandyopadhyay ${ }^{1}$, Cecile

Nasarre $^{1}$, Gyda Beeson ${ }^{1}$, Richard Comer $^{1}$, Christopher Lindsey ${ }^{1}$, Rick Schnellmann ${ }^{2}$, and Baerbel Rohrer ${ }^{1}$

${ }^{1}$ Med Univ S Carolina

${ }^{2}$ University of Arizona

September 8, 2020

\begin{abstract}
Metabolic stress and associated mitochondrial dysfunction are implicated in retinal degeneration irrespective of the underlying cause. We identified seven unique chemicals from a screen of the Chembridge DiverSET and tested their protection against calcium ionophore and IBMX-induced loss of mitochondrial capacity, as measured by viability and respirometry, in mouse retinal photoreceptor-derived $661 \mathrm{~W}$ cells. Six of the agents $(\mathrm{CB} 1,2,6,1011,12)$ were protective. Cheminformatic analyses identified a unique pharmacophore with 6 physico-chemical features based on two of the compounds (CB11 and CB12). The protective efficacy of CB11 was further shown by a decrease in the loss of rod photoreceptor cells in retinal explants from two retinitis pigmentosa rodent models, the rd1 mouse and the S334ter-line-3 rat exposed to CB11 in the media. Using eye drops, CB11 biodistribution was confirmed in the retina of the pig eye. The same eye drops decreased photoreceptor cell loss in Balb/c mouse exposed to constant light, a model of age-related macular degeneration. Our studies have identified new chemicals that protect from mitochondrial damage and leads to improved mitochondrial function. Using ex vivo and in vivo models, CB11 decreased the loss of photoreceptor cells in murine models of retinal degeneration and may be effective in the treatment of a wide variety of retinal dystrophies.
\end{abstract}

\section{Hosted file}

Rohrer MCT_Screen Manuscript 063020.doc available at https://authorea.com/users/357382/ articles/479931-newly-identified-chemicals-preserve-mitochondrial-capacity-anddecelerate-loss-of-photoreceptor-cells-in-murine-retinal-degeneration-models

A<smiles>C=Nc1ccccc1NC1=CC(=O)CC(C)(C)C1</smiles>

CB2<smiles>CCOC(=O)C(=NC1(C)Cc2ccccc2CC1(C)C)C(=O)O</smiles>

CB3<smiles>COc1ccc(C(=O)NC2C=CC(=O)CC2(C)C)cc1</smiles>

CB11

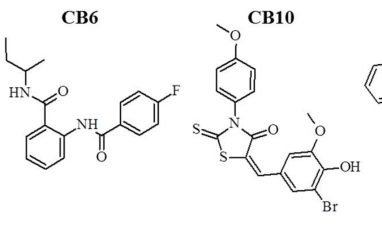<smiles>CCCCN1C(=O)C(O)(CC(O)c2ccccn2)c2ccccc21</smiles>

CB12

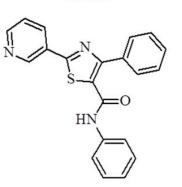

B

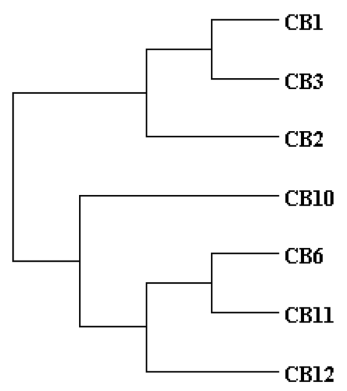




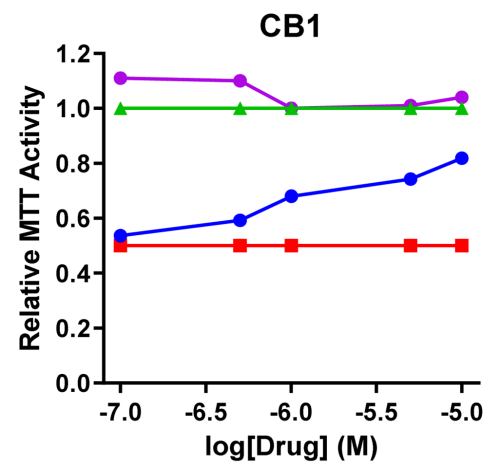

Legend:

- Drug + A23187

$\rightarrow$ A23187 (1 $\mu \mathrm{M})$

$\leftarrow$ Vehicle

$\rightarrow$ Drug Alone
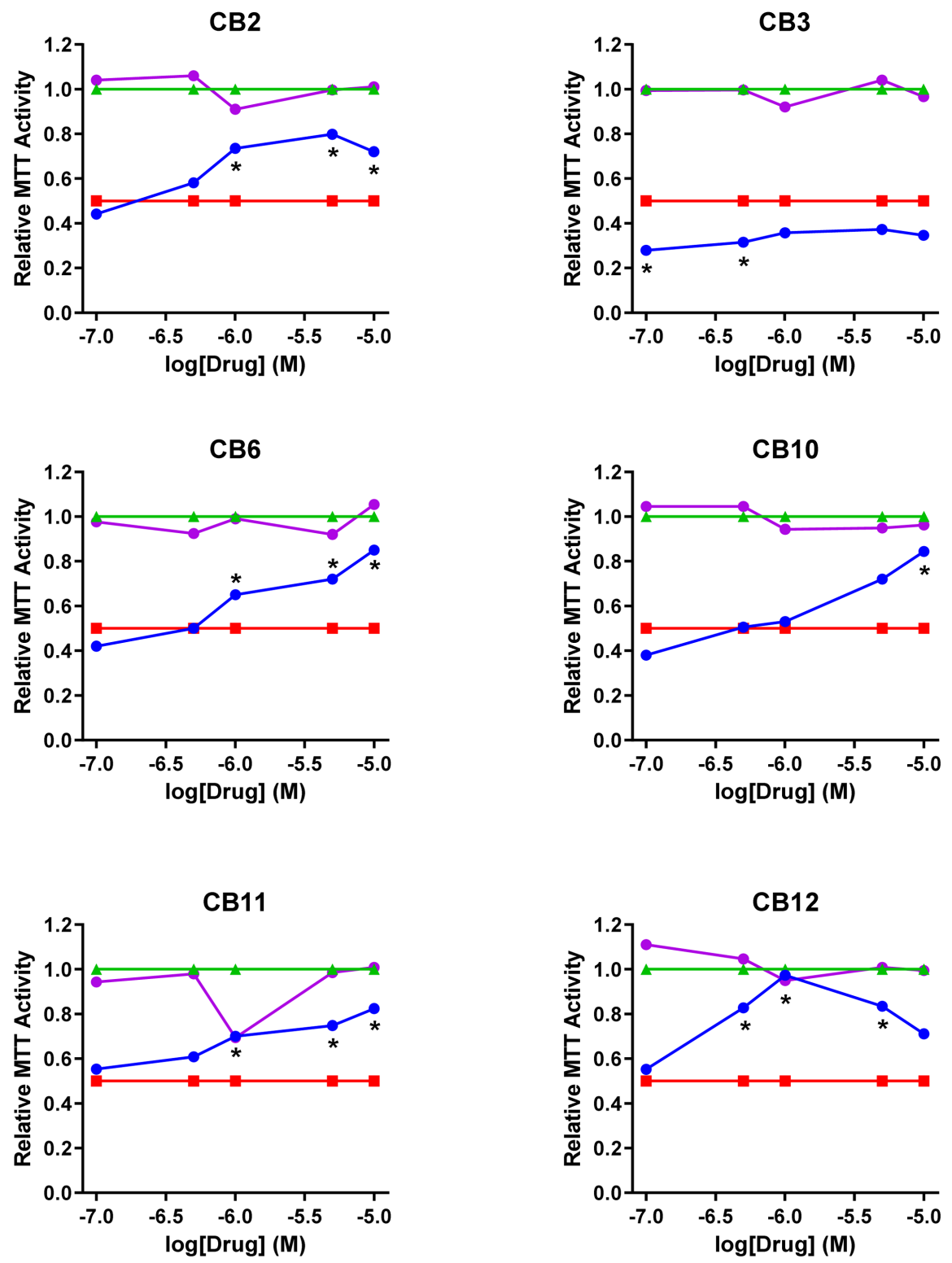

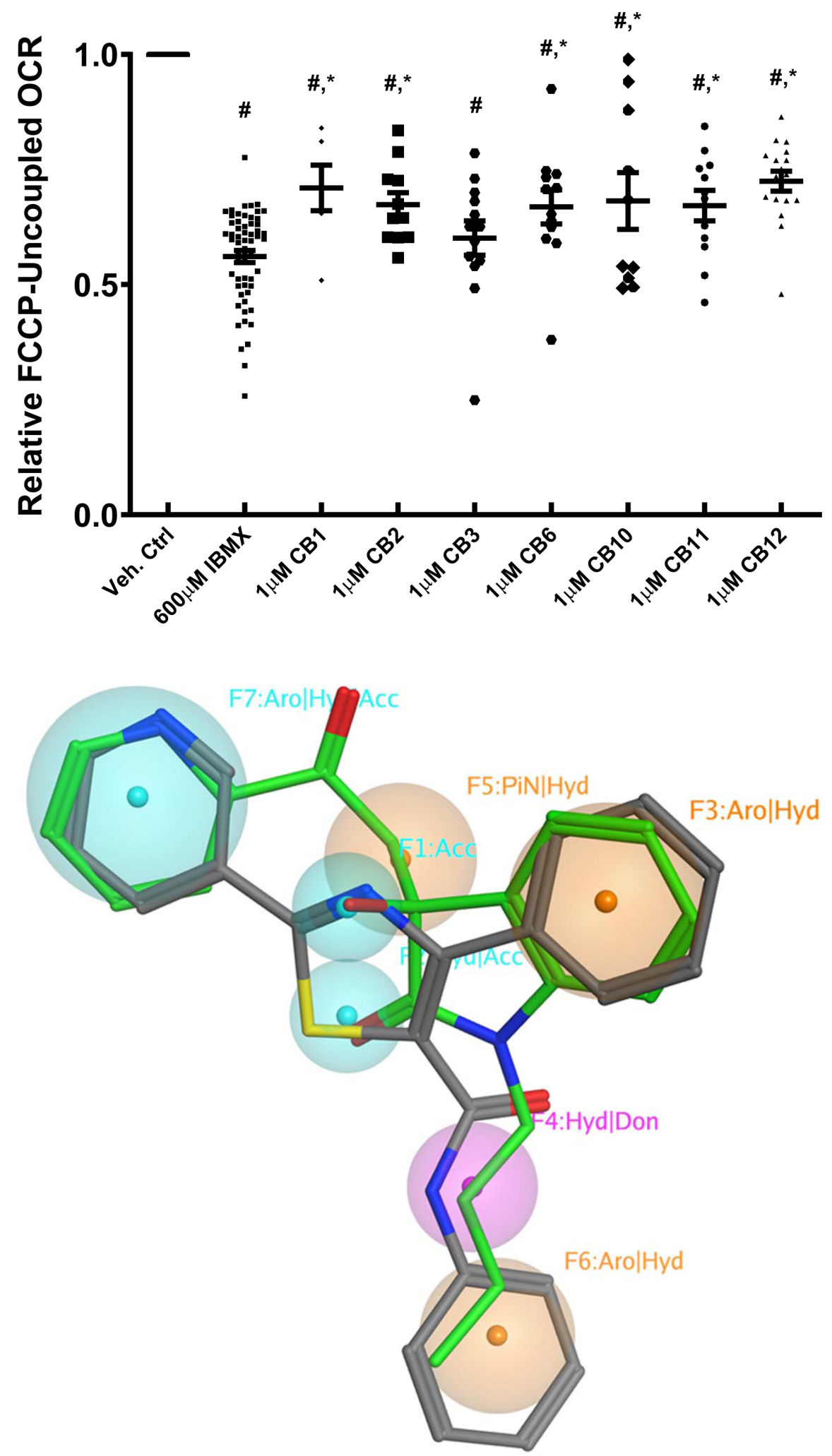
A

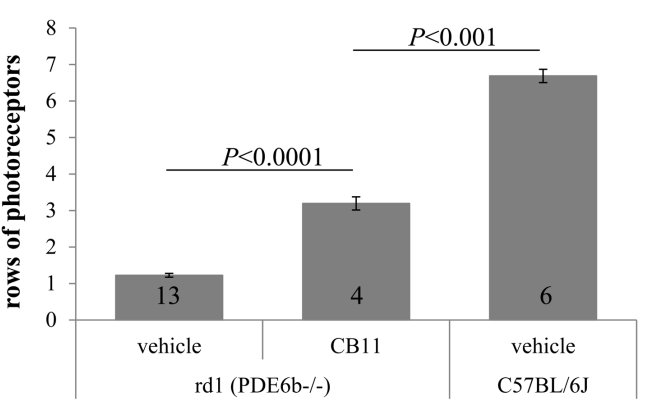

B

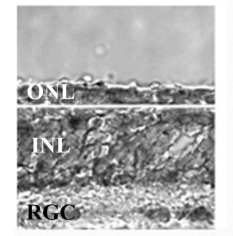

rd1 + vehicle

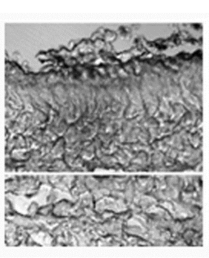

rd1 + CB11 WT + vehicle
C

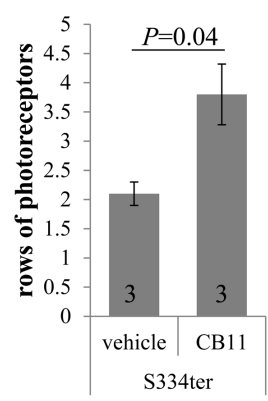

D

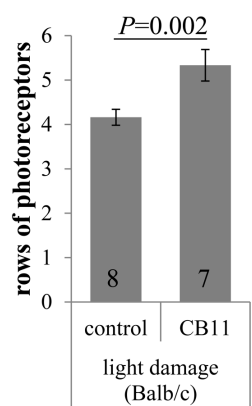


A

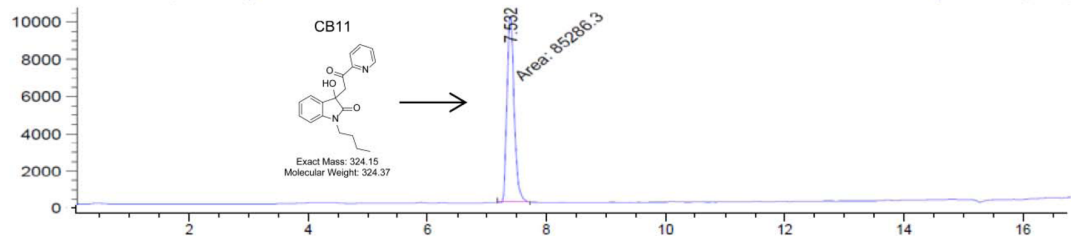

B

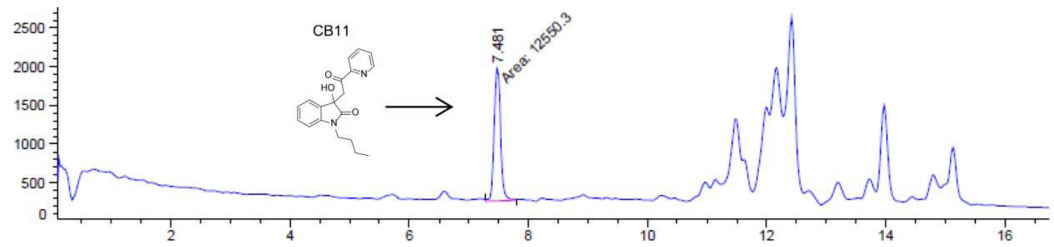

C

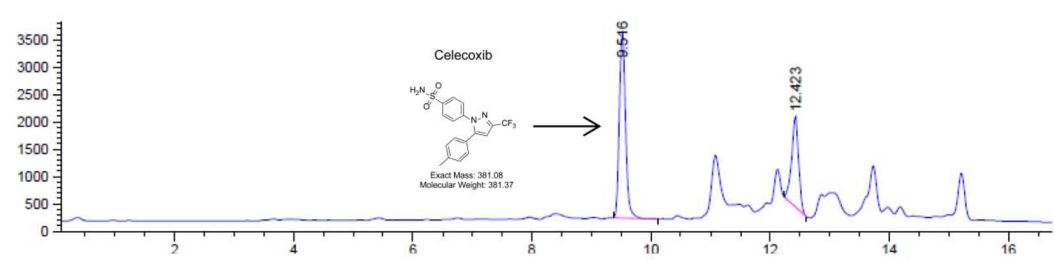

D

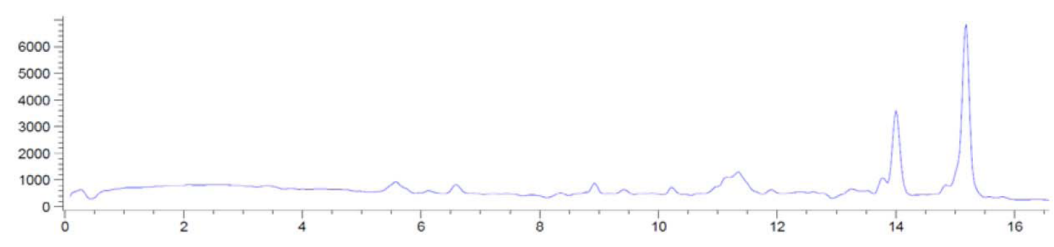

retention time [minutes] 